\title{
Groundwater and surface-water utilisation using a bank infiltration technique in Malaysia
}

\begin{abstract}
Bank infiltration (BI) is one of the solutions to providing raw water for public supply in tropical countries. This study in Malaysia explores the use of BI to supplement a polluted surface-water resource with groundwater. Three major factors were investigated: (1) contribution of surface water through BI to the resulting abstraction, (2) input of local groundwater, and (3) water-quality characteristics of the resulting water supply. A geophysical method was employed to define the subsurface geology and hydrogeology, and isotope techniques were performed to identify the source of groundwater recharge and the interaction between surface water and groundwater. The physicochemical and microbiological parameters of the local surface-water bodies and groundwater were analyzed before and during water abstraction. Extracted water revealed a 5-98 \% decrease in turbidity, as well as reductions in $\mathrm{HCO} 3-, \mathrm{Cl}-, \mathrm{SO} 42-, \mathrm{NO} 3-, \mathrm{Ca} 2+, \mathrm{Al}+$ and As concentrations compared with those of Langat River water. In addition, amounts of E. coli, total coliform and Giardia were significantly reduced $(99.9 \%)$. However, water samples from test wells during pumping showed high concentrations of $\mathrm{Fe} 2+$ and $\mathrm{Mn} 2+$. Pumping test results indicate that the two wells used in the study were able to sustain yields.
\end{abstract}

Keyword: Bank infiltration; Hydrochemistry; Alluvial aquifer; Groundwater/surface water relations; Malaysia 